\title{
Depression Among Non-Cancer Chronic Pain Patients at a Tertiary Hospital in Malaysia
}

\author{
Rajesh KM $M^{\mathrm{a}}$, T Kumaravadivel $\mathrm{D}^{\mathrm{b}}$ \\ ${ }^{a}$ Medicine Based Department, Faculty of Medicine and Health Sciences, Universiti Malaysia Sabah, Kota Kinabalu, Sabah, Malaysia. \\ ${ }^{\mathrm{b}}$ Department of Anaesthesiology and Critical Care, Hospital Teluk Intan, Teluk Intan, Perak Darul Ridzuan, Malaysia.
}

\begin{abstract}
INTRODUCTION: Pain is as important public health concern. Chronic pain patients most frequently present with depression, and this needed to be treated. The aim of the study was to find the prevalence of depression among non-cancer chronic pain patients attending a Pain Clinic in Malaysia, and discuss possible treatment methods to help these patients. MATERIAL AND METHODS: Inclusion criteria were all non- cancer chronic pain patients who visited the Pain Clinic of Queen Elizabeth Hospital (QEH), Kota Kinabalu, Sabah from 2013 till 2017. All patients were required to fill a PainDetect form and a Patient Health Questionnaire-9 (PHQ-9). RESULTS: Two hundred and fifty-four patient's case notes were analysed. The results show that $29.6 \%$ patients had mild depression, with $34.4 \%$ of patients had moderate to severe depression. There was a significant correlation between pain scores and depression. There was also a significant correlation between PainDetect scores and depression.
\end{abstract} CONCLUSION: There is a high prevalence of depression among non-cancer chronic pain patients. This study shows that psychological treatment for all chronic pain patients is needed.

KEYWORDS: depression, chronic pain, painDetect, Patient Health Questionnaire-9 (PHQ-9)

\section{INTRODUCTION}

World Health Organisation (WHO) recognizes pain as an important health concern. ${ }^{1}$ A survey done in various primary healthcare clinics indicated that the prevalence of chronic pain was $20-30 \% .^{2}$ Chronic pain is a highly prevalent condition which significantly impacts the health and quality of life. ${ }^{3}$ The prevalence of chronic pain among Malaysians is noted to be at $7 \%$ in a study conducted in 2002, seen more in elderly people. ${ }^{4}$

To complicate the situation further, chronic pain patients are also seen to experience depression. ${ }^{5}$

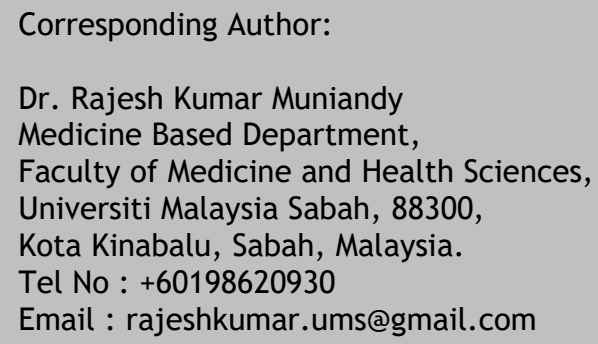

Depression is a common emotional condition seen in chronic pain patients. ${ }^{6}$ Studies reported that multiple pain symptoms (headache, back pain and knee pain) and the worsening of pain symptoms (severity, duration, and frequency) leave patients more prone to experience depression. ${ }^{7}$ Studies have also shown that there is a higher probability of patients with chronic pain developing depressive symptoms compared to the general population. ${ }^{8}$ Studies also revealed that the depression symptoms will prevails as the pain severity worsens. 9,10 In Malaysia, the prevalence of depression in the general population is about 8 to $12 \% .{ }^{11}$

This study aims to find the prevalence of depression among non-cancer chronic pain patients attending a Pain Clinic in Malaysia, and discuss possible treatment methods to help these patients. 


\section{MATERIALS AND METHODS}

\section{Study design and participation}

A universal sampling technique was used. Inclusion criteria were all non- cancer chronic pain patients who visited the Pain Clinic QEH, Kota Kinabalu, Sabah from the year 2013 till 2017. Chronic pain is defined as pain persisting more than three to six months. ${ }^{12}$ Exclusion criteria include incomplete case notes, cancer pain patients and patients with existing psychiatric problems. Two hundred and fifty-four case notes were collected and analysed. This study was registered with the National Medical Research Registry, Ministry of Health Malaysia.

\section{Data Collection}

Case notes which fulfilled our criteria were selected and the data was extracted by two trained personnel. Demographic data such as age, gender, history of surgical intervention, religion, marital status, Numerical rating Pain Score, and duration of pain experienced were collected. All patients were required to fill a PainDetect form and a Patient Health Questionnaire-9 (PHQ-9) during their visit to our pain clinic. Data were extracted and analysed.

\section{Study Instrument}

A Numeric Rating Scale (NSR) was used to evaluate the intensity of the pain. The scale ranges from 0 to 10 , with 0 being no pain experienced, and 10 being the worst pain imaginable. The NSR is a practical scale, which is easier to understand, and does not require clear vision, dexterity, paper or pen. ${ }^{13}$

PainDETECT is a screening tool developed in Germany to detect neuropatbic component in patients with back pain. This screening tool has shown applicability also to patients with other types of neuropathic pain. It is a self-reported questionnaire, consisting of nine items, seven of which are sensory descriptor, and the other two items are related to the spatial (radiating) and temporal characteristics of the individual pain pattern. It has a sensitivity and specificity of $85 \%$ and $80 \%$ respectively, compared to clinical diagnosis. ${ }^{14}$ Total scores of $\leq 12$ is interpreted as where the neuropathic component is unlikely and score of $\geq 19$ as where the neuropathic component is highly likely. ${ }^{14}$

The PHQ-9 is a valid tool consisting of nine questions based on the Diagnostic and Statistical Manual of Mental Disorder (DSM) IV criteria for major depression. It is useful to detect for probable major depressive disorder (MDD). Its validity as a brief depression severity measure was announced in 2001.15

As a severity measure, the PHQ-9 scores range from 0 to 27 , as each item scored from 0 (not at all) to 3 (nearly every day). In this study, the validated Malay version of PHQ-9 was used to assess the depression levels among patients. ${ }^{16}$ The internal reliability of PHQ-9 was good, with a Cronbach's (alpha) of 0.67. Test-retest reliability had an alpha of 0.73.17 PHQ-9 scores of 5, 10, 15, and 20 represented mild, moderate, moderately severe, and severe depression respectively. 15

\section{Statistical Analysis}

The collected data were compiled into a set of systematic and computerised data via the IBM Statistical Package of Social Sciences (SPSS) version 22.0 software. The analysis of the present study was divided into descriptive and inferential analyses.

\section{RESULTS}

\section{Demographic profile}

A total of two hundred and fifty-four patient's case notes were analysed, age ranging from 17 to 84 years old with mean age of 48.44(SD=17.44). Majority of the patients were female $(\mathrm{N}=155,61 \%)$. Most of the patients presented to us suffered in pain for more than one year and experienced moderate to severe pain (Pain score $>6$ ). Table 1 shows the summary of the demographic profile. 
Table 1: Demographic data of patients attending Pain Clinic

\begin{tabular}{|c|c|}
\hline Demographic & $\mathbf{N}(\%)$ \\
\hline $\begin{array}{l}\text { Gender: } \\
\text { Male } \\
\text { Female }\end{array}$ & $\begin{array}{l}99(39.0) \\
155(61.0)\end{array}$ \\
\hline $\begin{array}{l}\text { History of surgical intervention done: } \\
\text { Yes } \\
\text { No }\end{array}$ & $\begin{array}{l}110(43.3) \\
144(56.7)\end{array}$ \\
\hline $\begin{array}{l}\text { Marital Status: } \\
\text { Single } \\
\text { Married } \\
\text { Widow } \\
\text { Divorced }\end{array}$ & $\begin{array}{l}54(21.3) \\
183(72) \\
8(3.1) \\
9(3.5)\end{array}$ \\
\hline $\begin{array}{l}\text { Religion: } \\
\text { Islam } \\
\text { Buddhist } \\
\text { Hindu } \\
\text { Christian }\end{array}$ & $\begin{array}{l}109(42.9) \\
39(15.4) \\
2(0.8) \\
104(40.9)\end{array}$ \\
\hline $\begin{array}{l}\text { Numeric Rating Scale (NSR) on rest: } \\
\text { Mild }(0-3) \\
\text { Moderate }(4-6) \\
\text { Severe }(7-10)\end{array}$ & $\begin{array}{l}21(8.3) \\
114(44.8) \\
119(46.9)\end{array}$ \\
\hline $\begin{array}{l}\text { Numeric Rating Scale (NSR) on movement: } \\
\text { Mild }(0-3) \\
\text { Moderate }(4-6) \\
\text { Severe }(7-10)\end{array}$ & $\begin{array}{l}8(3.1) \\
81(31.9) \\
165(65.0)\end{array}$ \\
\hline $\begin{array}{l}\text { Pain characteristic: } \\
\text { Persistent pain with slight fluctuation } \\
\text { Persistent pain with attacks } \\
\text { Pain attacks without pain in between } \\
\text { Pain attacks with pain between them }\end{array}$ & $\begin{array}{l}41(16.1) \\
26(10.3) \\
143(56.3) \\
44(17.3)\end{array}$ \\
\hline $\begin{array}{l}\text { Pain radiates to other region } \\
\text { Yes } \\
\text { No }\end{array}$ & $\begin{array}{l}147(57.9) \\
107(42.1)\end{array}$ \\
\hline $\begin{array}{l}\text { Duration of pain } \\
\text { Less } 1 \text { year } \\
1-3 \text { years } \\
>3-5 \text { years } \\
>5-10 \text { years } \\
>10 \text { years }\end{array}$ & $\begin{array}{l}48(18.9) \\
106(41.7) \\
41(16.2) \\
39(15.3) \\
20(7.9)\end{array}$ \\
\hline
\end{tabular}

Depression score among chronic pain patients

The study shows that $29.6 \%$ of patients had mild depression. Another $34.4 \%$ of patients had moderate to severe depression. Only $35.8 \%$ patients scored to be normal without depression. (Table 2)

Table 2: Descriptive profiles of depression among patients

\begin{tabular}{lc}
\hline PHQ-9 score (Depression level) & $\mathrm{N}(\%)$ \\
\hline Normal (0-4) & $91(35.8)$ \\
Mild (5-9) & $75(29.6)$ \\
Moderate (10-14) & $49(19.2)$ \\
Moderate-severe (15-19) & $18(7.1)$ \\
Severe (20-27) & $21(8.3)$ \\
\hline
\end{tabular}

\section{Neuropathic pain}

From the painDETECT score analysis, $29.1 \%$ of the patients had possible neuropathic pain. Another 33.9\% patient was likely having neuropathic pain. Only $37 \%$ of the patients did not have neuropathic pain.

\section{Correlation among age, pain score, duration and depression score}

Bivariate analysis using Pearson correlation was performed to analyse the correlation between depression score with age, neuropathic pain, pain duration and pain score. There was a significant correlation between pain scores and depression. $(\mathrm{r}=0.19, \quad \mathrm{p}<0.001) \quad$ There was also a significant correlation between depression and the painDETECT scores $(r=0.24, p<0.001)$. This shows that depression is seen more in patients having higher pain scores and are likely with neuropathic pain. However, there was no significant correlation between depression and age or pain duration. (Table 3) The pain score refers to the severity of the pain, and the painDETECT score refers to the neuropathic component of pain.

Table 3: Pearson correlation coefficients between age, pain score, pain duration, depression and painDETECT scores.

\begin{tabular}{lccccc}
\hline & 1 & 2 & 3 & 4 & 5 \\
\hline Age & 1 & & & & \\
Pain Score & .003 & 1 & & & \\
Pain Duration & .014 & .018 & 1 & & \\
Depression Score & -.024 & $.191^{* *}$ & .039 & 1 & \\
PainDETECT Score & $-.025^{* *}$ & $.27^{* *}$ & .001 & $.24^{* *}$ & 1 \\
\hline \multicolumn{7}{c}{ difference } & between & depression & and \\
Mean & & & & &
\end{tabular}

Independent T-test and one way ANNOVA was performed to look for mean difference between demographic subgroups. There was no significant difference noted. We can conclude that the depression score in our patients are not affected by their religion, marital status, gender or pain characteristic.

\section{DISCUSSION}

Our study showed that $64.2 \%$ of the patients attending Pain Clinic at Queen Elizabeth Hospital meet the 
criteria for probable Major Depressive Disorder (MDD). This results was similar to a study done in the United Kingdom (60.8\%), ${ }^{18}$ but higher than a similar study done in a Malaysian hospital located near Kuala Lumpur (37.4\%). ${ }^{19}$

Chronic pain patients who are having depression are more likely to have an increased pain intensity, a lower pain threshold, and may show diminished capability to cope with pain. This will translate to an increased doctor visits, longer hospital stay and more treatment modalities. ${ }^{20}$ This will therefore increase the economic burden on society especially in terms of medical care and loss of productivity. Since a correlation between depression and chronic pain is already identified, there may be an opportunity to reduce the impact on both economy and society. This would also mean that early detection of depression among these patients should be a priority among healthcare providers.

Chronic pain is usually managed in a multi-modal approach. Besides pharmacological treatment, other possible treatment methods include pain intervention procedures, physiotherapy, group therapy and acupuncture. Several of these modalities are usually used together at the same time in a patient, thus producing a balance between pharmacological and nonpharmacological treatment.

There is a growing acceptance that psychological treatment in combination with physical or pharmacological treatment, can be used to manage chronic pain. ${ }^{21}$ Therefore, it would be effective if a chronic pain patient is managed by a multidisciplinary team. The team usually includes a physician, psychologist, physical therapist, occupational therapist, social workers, and nurses. ${ }^{22}$ However, not all pain clinic practices have this luxury. Nevertheless, healthcare practitioners involved in the management of chronic pain patients can acquire the skill to perform basic psychological treatments.

Psychological treatment is divided into behavioural (biofeedback, relaxation, contingency management, or exposure) and cognitive behavioural (coping strategies, education, cognitive therapy). ${ }^{23}$ Cognitive Behavioural Therapy (CBT) is the psychological treatment for chronic pain patients. ${ }^{24}$ Among the goals of CBT is to reduce pain and also psychological distress. It aims to improve physical and role function by helping patients to decrease maladaptive behaviours while increasing adaptive behaviours, identify and correct their maladaptive thoughts and beliefs, and increase selfefficacy for pain treatment.

The key components of CBT are education, skills acquisition, skills consolidation, and generalisation and maintenance. ${ }^{25}$

Table 4: The key components of CBT

\begin{tabular}{lll}
\hline $\begin{array}{l}\text { Key } \\
\text { components }\end{array}$ & \multicolumn{1}{c}{ Objective } & Action \\
\hline Education & $\begin{array}{l}\text { To create awareness } \\
\text { of the thoughts }\end{array}$ & $\begin{array}{l}\text { Challenge their } \\
\text { negative perceptions }\end{array}$ \\
$\begin{array}{l}\text { Skills acquisition } \\
\text { and } \\
\text { consolidation }\end{array}$ & $\begin{array}{l}\text { To help patients learn } \\
\text { and practice } \\
\text { behaviours and } \\
\text { cognition techniques }\end{array}$ & $\begin{array}{l}\text { Relaxation } \\
\text { Problem solving } \\
\text { distractions } \\
\text { activity pacing } \\
\text { communication }\end{array}$ \\
$\begin{array}{l}\text { Generalization } \\
\text { and } \\
\text { maintenance }\end{array}$ & To prevent relapse & \begin{tabular}{l} 
Home practice \\
\hline
\end{tabular} \\
\hline
\end{tabular}

\section{CONCLUSION}

There is a high prevalence of depression among noncancer chronic pain patients attending the pain clinic in Kota Kinabalu, Sabah. This study proves the need for psychological treatment to patients with chronic pain. There has always been a strong evidence that psychological treatment for chronic pain can reduce depression. ${ }^{26}$ Healthcare providers in the pain clinic must be adequately equipped to identify and manage patients with high probability of depression.

\section{STUDY LIMITATION}

One of the limitations of this study was that there might be a potential for misclassification of exposure. Although the PHQ-9 is highly sensitive and uses the 9 core DSM-V criteria for depression, it cannot replace the gold standard clinical interview. Several symptoms asked in PHQ-9 may also be present in both depression and pain.

\section{ACKNOWLEDGEMENT}

Thank you to the Director General of Health Malaysia for his permission to publish this article. 


\section{DISCLOSURES}

No funding was obtained in this research or preparation of this manuscript.

\section{CONFLICT OF INTEREST}

There is no conflict of interest in this research.

\section{REFERENCES}

1. WHO Normative Guidelines on Pain Management. http://www.who.int/medicines/areas/ quality_safety/delphi_study_pain_guidelines.pdf. 2007.

2. Gureje, O., Von Korff, M., Simon, G.E., Gater, R. Persistent pain and well-being. A World Health Organization study in primary care. JAMA 1998; 280(13):1142.

3. Tunks, E.R., Crook, J., Weir, R. Epidemiology of chronic pain with psychological comorbidity: prevalence, risk, course, and prognosis. Can J Psychiatry 2008; 53(4):224-234.

4. Cardosa, M.S., Gurpreet, R., Tee, H.G.T. Chronic Pain, The Third National Health and Morbidity Survey. Kuala Lumpur: Institute for Public Health, Ministry of Health Malaysia 2008; p. 262.

5. Ling, L.A., Peng, Y.B. Comorbidity of Depression and Pain: A review of shared contributing mechanisms. J Neurol Neuromed 2017;2(3):4-11.

6. Adam, K.M.Woo. Depression and Anxiety in Pain. Rev Pain 2010;4(1): 8-12. doi: $10.1177 / 2049463710004001034$.

7. Von Korff, M., Dworkin, S.F., Le Resche, L., Kruger, A. (1998). An epidemiologic comparison of pain com-plaints. Pain 1998;32:173-183.

8. Ozminkowski, R.J., Musich, S., Bottone, F.G.J., Hawkins, K., Bai, M., Unutzer, J., Hommer, C.E., Migliori, R.J., Yeh, C.S. The burden of depressive symptoms and various chronic conditions, and health concerns on the quality of life among those with Medicare Supplement Insurance. Int J Geriatr Psychiatry 2012;27(9):948-958.

9. Carroll, L.J., Cassidy, J.D., Cote, P. The Saskatchewan Health and Back Pain Survey: the prevalence and factors associated with depressive symptom- atology in Saskatchewan adults. Can J Public Health 2000;91:459-464.
10. Lamb, S., Guralnik, J., Buchner, D., Ferruci, L., Hochberg, M., Simonsick, E., Fried, L. Factors that modify the association between knee pain and mobility limitation in older women: the Women's Health and Aging Study. Ann Rheum Dis 2000; 59 (5):331-337.

11. Ng, C.G. A Review of Depression Research in Malaysia. Med J Malaysia 2014; Vol 69 Supplement A.

12. Merskey, H., Bogduk, N. Classification of chronic pain. $2^{\text {nd }}$ ed. Seattle:IASP Press 1994.

13. Breivik, H., Borchgrevink, P.C., Allen, S.M., Rosseland, L.A., Romundstad, L., Breivil Hals, E.K., Kvarsteij, G., Stubhaug, A. Assessment of Pain. Br J Anaesth 2008; 101(1):17-24.

14. Freynhagen, R., Baron, R., Gockel, U., Tölle, T.R. PainDETECT: a new screening questionnaire to identify neuropathic components in patients with back pain. Curr Med Res Opin 2006; 22(10): 19111920.

15. Kroenke, K., Spitzer, R.L., Williams, J.B.W. The PHQ-9. Validity of a brief depression severity measure. Journal of Gen Intern Med 2001;16(9): 606-13.

16. Sherina, M.S., Arroll, B., Goodyear-smith, F. Criterion validity of the PHQ-9 (Malay version) in a Primary Care Clinic in Malaysia. MedJ Malaysia 2012;67(30):309-315.

17. Azah, N.M.N., Shah, M.M.E., Juwita, S., Bahri, S.I., Rushidi, W.M., Jamil, M.Y. Validation of the Malay version brief Patient Health Questionnaire (PHQ-9) among adults attending family medicine clinics. Int Med J 2005; 12(4):259-63.

18. Rayner, L., Hotopf, M., Petkova, H., Matcham, F., Simpsom, A., McCracken, L.M. Depression in patients with chronic pain attending a specialised pain treatment centre: prevalence and impact on health care costs. Pain 2016;157(7):1472-1479.

19. Seed, H.F., Zakaria, H., Perumal, M., Baharudin, A. Depression among chronic pain patients at Hospital Ampuan Rahimah, Klang. Med J Malaysia 2015; 70 (5):303-306.

20. Sternke, E.A., Abrahamson, K., Bair, M.J. Comorbid chronic pain and depression: patient perspectives on empathy. Pain Manag Nurs 2017; 17(6):363-371.

21. IASP Recommendations for Pain Treatment Services. Available from http://www.iasp-pain.org/ 
AM/Template.cfm?

Section $=$ Pain_Treatment_Facilities $\&$ Template $=$ /

$\mathrm{CM} /$ HTMLDisplay.cfm $\&$ ContentID $=9218$

22. Sanders, S. H., Harden, R.N., Vicente, P. J.

Evidence-based clinical practice guidelines for interdisciplinary rehabilitation of chronic nonmalignant pain syndrome patients. Pain Pract 2005;5(4):303-315.

23. Eccleston, C., Morley, S.J., Williams, A.C.C. Psychological approaches to chronic pain management: Evidence and challenges. Br J Anaesth 2013;111(1):59-63.

24. Ehde, D.M., Dillworth, T.M., Turner, J.A. Cognitive-behavioral Therapy for individuals with chronic pain: Efficay, innovations and directions for research. Am Psychol 2014;69(2):153-166.

25. Turk, D. C. Cognitive-behavioural approach to the treatment of chronic pain patients. Reg Anesth Pain Med 2003;28 (6):573-579.

26. Williams, A.C., Eccleston, C., Morley, S. Psychological therapies for the management of chronic pain (excluding headache) in adults. Cochrane Database Syst Rev 2012;11:CD007407. 